\title{
A Combined High-Temperature Experimental and Theoretical Kinetic Study of Dimethyl Carbonate with $\mathrm{OH}$ Radicals
}

Fethi Khaled $^{1}$, Binod Raj Giri ${ }^{*}$, Milán Szőri ${ }^{2}$, Tam V.-T. Mai ${ }^{3}$, Lam K. Huynh ${ }^{4 *}$, Aamir Farooq ${ }^{1}$

${ }^{1}$ Clean Combustion Research Center, Division of Physical Sciences and Engineering, King Abdullah University of Science and Technology, Thuwal 23955-6900, Saudi Arabia

${ }^{2}$ Institute of Chemistry, Faculty of Materials Science and Engineering, University of Miskolc, Egyetemváros A/4., H-3515 Miskolc, Hungary

${ }^{3}$ Institute for Computational Science and Technology, SBI Building, Quang Trung Software City, Tan Chanh Hiep Ward, District 12, Ho Chi Minh City, Vietnam.

${ }^{4}$ International University, Vietnam National University - HCMC, Quarter 6, Linh Trung Ward, Thu Duc District, Ho Chi Minh City, Vietnam.

*Corresponding authors email: $\quad$ binod.giri@kaust.edu.sa; lamhuynh.us@gmail.com 


\begin{abstract}
Reaction kinetics of dimethyl carbonate (DMC) and $\mathrm{OH}$ radicals were investigated behind reflected shock waves over the temperature range of 872-1295 $\mathrm{K}$ and pressures near $1.5 \mathrm{~atm}$. Reaction progress was monitored by detecting $\mathrm{OH}$ radicals at $306.69 \mathrm{~nm}$ using a UV laser absorption technique. Rate coefficients for the reaction of DMC with $\mathrm{OH}$ radicals were extracted using a detailed kinetic model developed by Glaude et al. (Proc. Combust. Inst. 2005, 30 (1), 1111-1118). Experimental rate coefficients can be expressed in Arrhenius form as: $k_{\text {expt' } 1}=5.15 \times 10^{13} \exp (-2710.2 / T) \mathrm{cm}^{3} \mathrm{~mol}^{-1} \mathrm{~s}^{-1}$. To explore detailed chemistry of $\mathrm{DMC}+\mathrm{OH}$ reaction system, theoretical kinetic analyses were performed using high-level $a b$ initio and master equation/Rice-Ramsperger-Kassel-Marcus (ME/RRKM) calculations. Geometry optimization and frequency calculations were carried out at the second-order Møller-Plesset (MP2) perturbation level of theory using the Dunning's augmented correlation consistent-polarized valence double- $\zeta$ basis set (aug-cc-pVDZ). The energy was extrapolated to the complete basis set using single point calculations performed at the $\operatorname{CCSD}(\mathrm{T}) / \mathrm{cc}-\mathrm{pV} X \mathrm{Z}$ (where $X=\mathrm{D}$, T) level of theory. For comparison purposes, additional ab intio calculations were also carried out using composite methods such as CBS-QB3, CBS-APNO, G3 and G4. Our calculations revealed that the Habstraction reaction of DMC by $\mathrm{OH}$ radicals proceeds via an addition elimination mechanism in an overall exothermic process, eventually forming dimethyl carbonate radicals and $\mathrm{H}_{2} \mathrm{O}$. Theoretical rate coefficients were found to be in excellent agreement with those determined experimentally.
\end{abstract}

Rate coefficients for $\mathrm{DMC}+\mathrm{OH}$ reaction were combined with literature rate coefficients of four straight chain methyl esters $+\mathrm{OH}$ reactions to extract site-specific rates of $\mathrm{H}$-abstraction from methyl esters by $\mathrm{OH}$ radicals. 


\section{Introduction}

There is an increasing interest in using fuel blends comprising of oxygenated organic compounds and conventional fuels to increase oxygen content of the fuels. Particularly, carbonates such as dimethyl carbonate (DMC) and diethyl carbonate (DEC) may prove to be good oxygenate additives to diesel fuels due to their very high oxygen contents $(53.3 \%$ and $40.6 \%$ by mass, respectively). These carbonates have high boiling points (363 K for DMC and $400 \mathrm{~K}$ for DEC) which can help reduce the Reid vapor pressure (RVP) of blended fuels. Such fuel blends can be environmentally friendly as they promote cleaner combustion. ${ }^{1,2}$ Furthermore, methyl esters form major components of biodiesel which is a promising alternative fuel because it has physical/chemical properties similar to conventional diesel and can be derived from renewable sources such as vegetable oils and animal fats. Efficient utilization of biofuels for practical applications requires detailed knowledge of their chemistry, particularly when these are used in reactivity-controlled modern low-temperature internal combustion engines. The reaction of hydroxyl radicals with oxygenated fuels is one of the most important primary oxidation pathways under combustion relevant conditions.

Dimethyl carbonate (DMC) is an interesting oxygenate that upon abstraction of hydrogen atom by $\mathrm{OH}$ radicals leads to the formation of methoxy formyl radical $\left(\mathrm{CH}_{3} \mathrm{OC}{ }^{\bullet}=\mathrm{O}\right)$ via the following reaction sequence:

$\mathrm{CH}_{3} \mathrm{OC}(\mathrm{O}) \mathrm{OCH}_{3}+\mathrm{OH} \rightarrow \mathrm{CH}_{3} \mathrm{OC}(\mathrm{O}) \mathrm{OCH}_{2} \bullet+\mathrm{H}_{2} \mathrm{O}$

$\mathrm{CH}_{3} \mathrm{OC}(\mathrm{O}) \mathrm{OCH}_{2} \bullet \mathrm{CH}_{3} \mathrm{OC}^{\bullet}(\mathrm{O})+\mathrm{CH}_{2}=\mathrm{O}$ 
Methoxy formyl radical is an important radical as its fate under combustion relevant conditions helps unravel the chemistry of a key moiety $\left(\mathrm{ROC}^{\bullet}=\mathrm{O}\right.$, where $\mathrm{R}$ is the alkyl chain) of oxygenated fuels. Branching ratios for thermal unimolecular decomposition of $\mathrm{ROC}^{\bullet}(\mathrm{O})$ to $\mathrm{R}^{\bullet}+\mathrm{CO}_{2}$ and $\mathrm{RO}^{\bullet}$ + CO appear to be critical for oxygenated fuels as the pathway leading to CO leads to larger soot reduction as opposed to the pathway leading to $\mathrm{CO}_{2}{ }^{3}$ The primary aim of the current work, however, is to understand the initial step for the formation of methoxy formyl radical by the reaction of $\mathrm{DMC}$ with $\mathrm{OH}$ radicals at high temperatures.

Pekeurt et al. ${ }^{1,4}$ investigated the reactions of DMC with $\mathrm{H}$ and $\mathrm{O}$ atoms at high temperatures. In addition, they also studied thermal decomposition of DMC and deuterated kinetic isotopic effect (DKIE) for bimolecular reactions of DMC with H/D. Glaude et al. ${ }^{5}$ recently developed a detailed kinetic model to understand the combustion of DMC in an opposed-flow diffusion flame. In this study, we present high-temperature rate constant measurements for the reaction of DMC with $\mathrm{OH}$ radicals and theoretically assess pressure- and temperature- dependence of the $\mathrm{DMC}+\mathrm{OH}$ reaction by employing $a b$ initio/RRKM-master equation calculations. To our knowledge, this is the first combined experimental and theoretical kinetic study to investigate the kinetics of $\mathrm{DMC}+\mathrm{OH}$ reaction under combustion relevant conditions.

Recently, Lam et al. ${ }^{6}$ measured rate coefficients for the reaction of hydroxyl radicals with four simple straight chain methyl esters behind reflected shock waves over the temperature range of $876-1371 \mathrm{~K}$ and pressure near $1.5 \mathrm{~atm}$. As the chemical environment of hydrogens in $-\mathrm{O}-\mathrm{CH}_{3}$ moiety of DMC is similar to that in straight chain methyl esters, we combine the high-temperature data of the current work with the data from Lam et al. ${ }^{6}$ to propose a group scheme within the NextNearest-Neighbor (N-N-N) methodology of Cohen et al. ${ }^{7}$ This allows us to estimate site-specific 
hydrogen abstraction rate coefficients of any straight chain methyl esters by $\mathrm{OH}$ radicals which will be useful to construct detailed kinetic model of oxygenated fuels.

\section{Computational Details}

Density functional methods (e.g., B3LYP) are frequently used for geometry optimization, however, their failure in locating the transition states for hydrogen abstraction reactions have been reported. ${ }^{8,9}$ These studies showed that MP2 transition state geometries are found to be close to those obtained from CCSD for hydrogen abstraction reactions by $\mathrm{OH}$ radicals. Therefore, all structures of stationary points along the reaction pathway for the reaction of $\mathrm{DMC}+\mathrm{OH}$ were optimized at the second-order Møller-Plesset (MP2) ${ }^{10,11}$ perturbation level of theory by using Dunning's augmented correlation consistent-polarized valence double- $\zeta$ basis set (aug-ccpVDZ $)^{12,13}$ and applying the "tight" convergence criterion. Optimized structures were then characterized at the same level of theory by normal mode analysis to confirm their identities on the potential energy surface (PES). Vibrational frequencies obtained at the MP2/aug-cc-pVDZ level of theory were scaled by a factor of $0.9615 .{ }^{14}$ These scaled vibrational frequencies $\left(v_{\mathrm{i}}\right)$ and rotational constants $(A, B$ and $C)$ are compiled in Table S1 (Supplementary Information). After transition state (TS) structures were located by searching for the first-order saddle points on the potential energy surface (PES) using the second derivative of energy, intrinsic reaction coordinate (IRC) calculations ${ }^{15,16}$ were performed at the MP2/aug-cc-pVDZ level of theory to obtain the corresponding pre-reaction (RC) and post-reaction complexes (PC).

For single-point energies, coupled-cluster calculations with single and double excitation ${ }^{17-19}$ including the perturbative treatment of triple excitation $(\operatorname{CCSD}(T))^{20}$ were performed. In order to get highly accurate energies, two-point extrapolation scheme of Truhlar ${ }^{21}$ was employed to obtain 
$\operatorname{CCSD}(\mathrm{T})$ energies at the complete basis set limit (CBS) by using Dunning's correlation-consistent polarized valance cc-pVXZ $(X=\mathrm{D}, \mathrm{T})^{12,13}$ basis sets. According to Truhlar's extrapolation scheme, the extrapolated total energy $\left(E_{\infty}{ }^{\text {tot }}\right)$ can be derived by using the following expression:

$E_{\infty}^{\text {tot }}=\frac{3^{\alpha}}{3^{\alpha}-2^{\alpha}} E_{3}^{H F}-\frac{2^{\alpha}}{3^{\alpha}-2^{\alpha}} E_{2}^{H F}+\frac{3^{\beta}}{3^{\beta}-2^{\beta}} E_{3}^{\text {corr }}-\frac{2^{\beta}}{3^{\beta}-2^{\beta}} E_{2}^{\text {corr }}$

where $E_{2}^{H F}$ and $E_{3}^{H F}$ stand for Hartree-Fock (HF) energies obtained at cc-pVDZ and cc-pVTZ basis sets, respectively, while $E_{2}^{\text {corr }}$ and $E_{3}^{\text {corr }}$ are the correlation energies obtained at the CCSD(T)/cc$\mathrm{pVDZ}$ and CCSD(T)/cc-pVTZ level of theory. Finally, $\alpha$ and $\beta$ are constants with values 3.4 and 2.4 for HF and CCSD(T) calculations, respectively. Along CCSD(T) calculations, $T_{1}$ diagnostics were also performed to assess the importance of non-dynamical correlation effects suggested by Lee and Taylor. ${ }^{22}$ In all cases, $T_{1}$ values were found to be less than 0.02 which indicated that either post $\operatorname{CCSD}(\mathrm{T})$ or multi-reference treatment of the system studied here was not necessary. For all post-HF calculations, the frozen core approximation was applied. Furthermore, composite

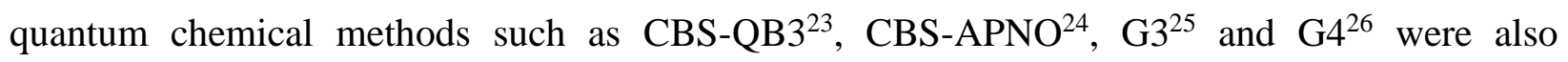
employed to compute the energetics of $\mathrm{DMC}+\mathrm{OH}$ reaction for comparison. However, we used the energetics and molecular parameters obtained at the $\operatorname{CCSD}(\mathrm{T}) / \mathrm{cc}-\mathrm{pV}(\mathrm{D}, \mathrm{T}) \mathrm{Z} / \mathrm{MP} 2 / \mathrm{aug}$-ccpVDZ levels of theory for kinetic analysis. All electronic structure calculations were carried out using the GAUSSIAN 09 package. ${ }^{27}$

Thermodynamic/kinetic calculations were carried out using the Multi-Species Multi-Channels (MSMC) code. ${ }^{28,29}$ In these calculations, overall rotations were treated classically and vibrations were treated quantum mechanically within the harmonic oscillator approximation except for the low bending modes corresponding to the internal rotations along the single $\mathrm{C}-\mathrm{C}$ and $\mathrm{C}-\mathrm{O}$ bonds. Partition functions of the hindered rotors were accurately obtained by solving the 1-D Schrödinger 
equation. Hindrance potentials $(V(\theta))$ of the internal rotors as a function of the torsional angle $(\theta)$ were explicitly obtained at the MP2/6-31G(d) level of theory via relaxed surface scans with a step size of $10^{\circ}$. Such potential energy surface scans are provided in Table S2 of the Supplementary Information. Procedural details of the hindered internal rotation (HIR) correction can be found elsewhere..$^{29}$ Temperature- and pressure- dependence of the title reaction were then computed within the master equation/Rice-Ramsperger-Kassel-Marcus (ME/RRKM) framework using both stochastic and deterministic approaches.

\section{Experimental Details}

Experiments were conducted in the low-pressure shock tube facility (LPST) at King Abdullah University of Science and Technology (KAUST) behind reflected shock waves over a temperature range of $872-1295 \mathrm{~K}$ and pressures near $1.5 \mathrm{~atm}$. Only a brief description of the shock tube facility is presented here; the details can be found elsewhere. ${ }^{30}$ The driver and driven sections of the LPST are $9 \mathrm{~m}$ long each with an inner diameter of $14.2 \mathrm{~cm}$. The length of the driver section can be varied according to the desired experimental test time. The driven and driver sections of the shock tube were filled with the test gas mixture and helium, respectively, and these were separated by a polycarbonate diaphragm. Prior to filling of the test gas mixture, the shock tube was turbo-pumped to a pressure of less than $10^{-5}$ mbar to ensure high purity of the reaction zone. Shock waves were generated by pressure bursting of the polycarbonate diaphragm using helium as the driver gas. Incident shock speed was measured by a series of five PCB 113B26 piezoelectric pressure transducers (PZTs) placed over the last $1.3 \mathrm{~m}$ of the driven section of the shock tube. Standard shock jump relations ${ }^{31,32}$, initial temperature and pressure and known thermodynamic parameters were used to calculate post-reflected shock conditions (P5 and T5) with a maximum uncertainty of $1 \%$. 
Hydroxyl radicals were produced by fast thermal decomposition of tert-butyl hydroperoxide (TBHP) which, as a clean $\mathrm{OH}$ precursor, has been validated in several earlier studies. ${ }^{30,33,34}$ The reaction kinetics of hydroxyl radicals were observed by probing the $\mathrm{R}_{1}(5) \mathrm{OH}$ absorption line in the $(0,0)$ band of the $\mathrm{A}^{2} \Sigma^{+} \leftarrow \mathrm{X}^{2} \Pi$ transition near $306.69 \mathrm{~nm}$. The UV light was generated by external frequency doubling of red light $(614 \mathrm{~nm})$ produced by a Sirah Matisse Ring-Dye laser which was pumped by a Spectra Physics CW laser at $532 \mathrm{~nm}$. For optical access, quartz windows were installed on the shock tube side-wall at $20 \mathrm{~mm}$ away from the end-wall of the shock tube. A common-mode-rejection scheme was used which gives an $\mathrm{OH}$ detection limit of about $0.2 \mathrm{ppm}$ at $1400 \mathrm{~K}$ and $1 \mathrm{~atm}$, assuming a minimum detectable absorbance of $0.1 \%$. Measured absorbance time-histories were converted into concentration time-histories using the Beer-Lambert law. Absorption coefficient of hydroxyl radical was obtained from previous studies. ${ }^{35,36}$

Test gas mixtures were prepared manometrically in a 24-litre teflon-coated stainless steel vessel equipped with a magnetically driven stirrer. Prior to mixture preparation, the vessel was pumped down to a pressure below $10^{-5}$ mbar. The mixtures were allowed to homogenize for at least two hours before use. All chemicals (a 70\% solution of TBHP in water and $\geq 99.9 \%$ dimethyl carbonate) were purchased from Sigma Aldrich. These were degassed several times before preparing final mixtures with argon (Linde, 99.999\%) as the diluent gas. The concentrations of reactants ( $\sim 300 \mathrm{ppm}$ DMC and $\sim 25 \mathrm{ppm}$ of TBHP in argon) were chosen such that $\mathrm{OH}$ decay follows pseudo-first order kinetics. 


\section{Results and Discussion}

\subsection{Experimental rate coefficients for $\mathrm{DMC}+\mathrm{OH}$ reaction}

Experiments were conducted behind reflected shock waves over the temperature range of $872-$ $1295 \mathrm{~K}$ and pressures of $\sim 1.5 \mathrm{~atm}$. A typical high-temperature experimental OH time-history is shown in Figure 1, where time zero indicates the arrival of reflected shock wave at the center of optical port.

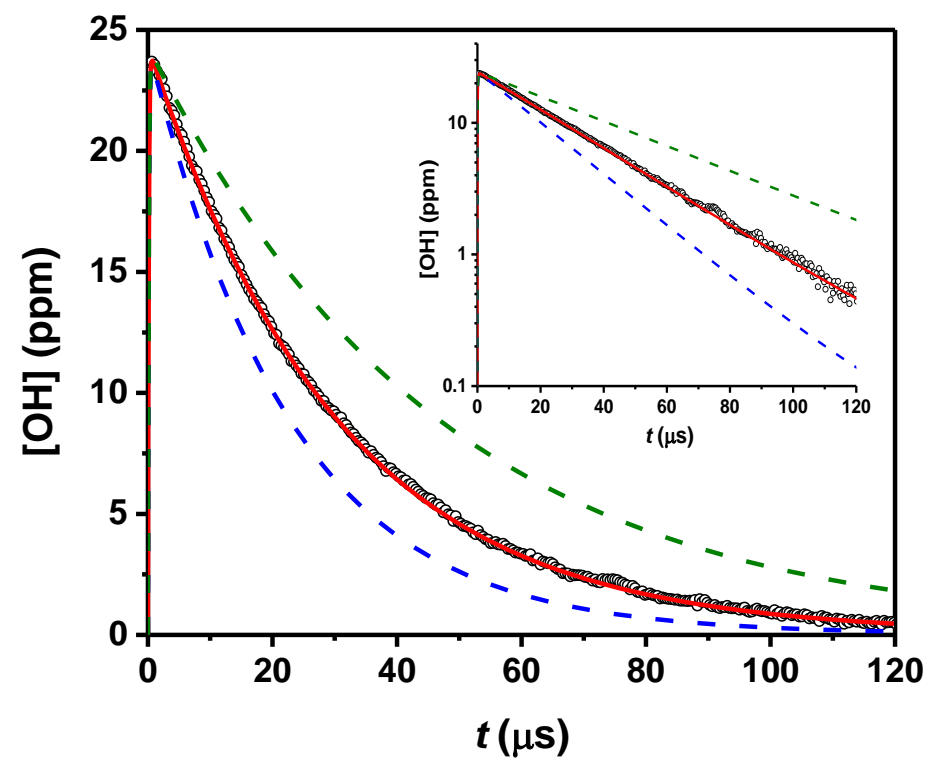

Figure 1: A typical $\mathrm{OH}$ concentration-time-profile measured at $T_{5}=1176 \mathrm{~K}$ and $P_{5}=1.43 \mathrm{~atm}$ for $280 \mathrm{ppm}$ of DMC and $24 \mathrm{ppm}$ of TBHP $\left(80 \mathrm{ppm} \mathrm{H}_{2} \mathrm{O}\right)$ in argon. The solid line represents the best fit $\left(\mathrm{k}=5.2 \times 10^{12} \mathrm{~cm}^{3} \mathrm{~mol}^{-1} \mathrm{~s}^{-1}\right)$ to the experimental profile and the dashed lines show perturbations of the rate coefficient from the best fit by $\pm 50 \%$. Inset displays $\ln [\mathrm{OH}]$ vs. time plot to show that $\mathrm{OH}$ decay follows first order kinetics.

As can be seen, $\mathrm{OH}$ radicals were formed almost instantaneously from the thermal decomposition of tert-butylhydroperoxide (TBHP) over a time scale of less than $1 \mu \mathrm{s}$. The $\mathrm{OH}$ radicals were then consumed primarily by the reaction with dimethyl carbonate, obeying first order kinetics (see inset 
of Figure 1). Sensitivity analysis was performed to identify the role of secondary reactions in $\mathrm{OH}$ loss. As shown in Figure 2, sensitivity analysis revealed minor interferences from secondary reactions such as $\mathrm{CH}_{3}+\mathrm{OH} \rightarrow \mathrm{CH}_{2}+\mathrm{H}_{2} \mathrm{O}, \mathrm{CH}_{3}+\mathrm{CH}_{3}(+\mathrm{M}) \leftrightarrow \mathrm{C}_{2} \mathrm{H}_{6}(+\mathrm{M})$, and $\mathrm{CH}_{3} \mathrm{COCH}_{3}+$ $\mathrm{OH} \rightarrow \mathrm{H}_{2} \mathrm{O}+\mathrm{CH}_{2} \mathrm{CO}+\mathrm{CH}_{3}$

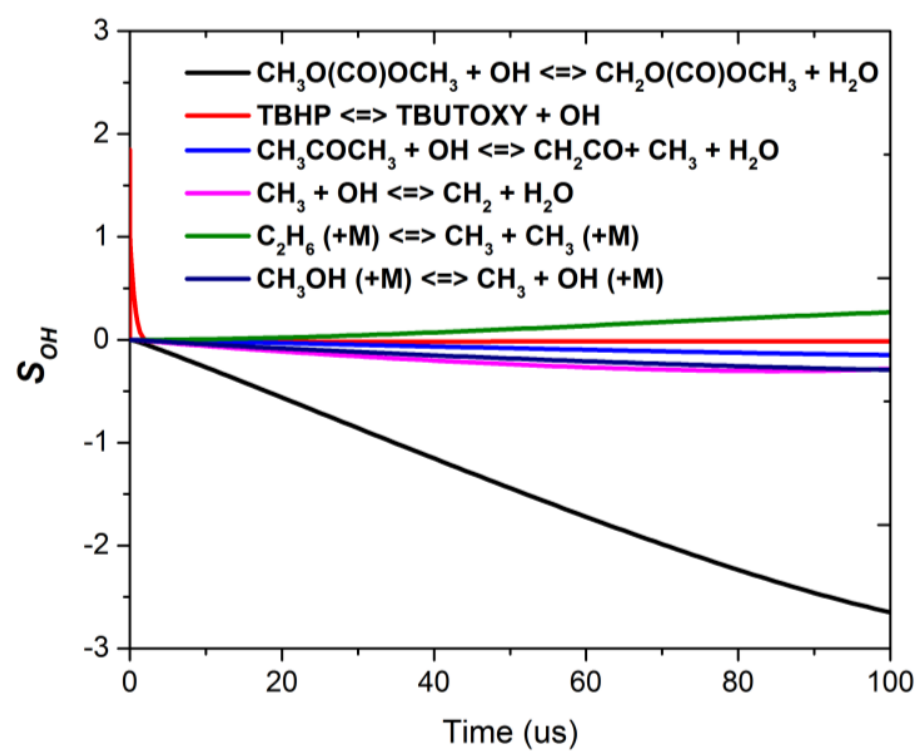

Figure 2: Hydroxyl sensitivity analysis for $\mathrm{DMC}+\mathrm{OH}$ reaction using the kinetic mechanism of Glaude et al. ${ }^{5}$ Conditions are same as in Fig. 1. Hydroxyl sensitivity is calculated as $S_{O H}=$ $\left(\frac{\partial X_{O H}}{\partial k_{i}}\right) *\left(\frac{k_{i}}{X_{O H}}\right)$ where $X_{O H}$ is the local $\mathrm{OH}$ mole fraction and $k_{i}$ is the rate coefficient for the $i$ th reaction.

Despite negligible importance of the secondary chemistry, rate coefficients for $\mathrm{DMC}+\mathrm{OH}$ reaction were extracted by using the detailed kinetic model developed by Glaude et al. ${ }^{5}$ for dimethyl carbonate. The TBHP sub-mechanism (see Pang et al. ${ }^{37}$ for details) was added to the base mechanism of Glaude et al..$^{5}$, whereas rate coefficients of the reactions of DMC with $\mathrm{O}$ and $\mathrm{H}$ atoms were updated from recent works of Peukert et al. ${ }^{1,4}$ During kinetic simulations, only the rate coefficient for the reaction of $\mathrm{OH}$ radicals with $\mathrm{DMC}$ was varied iteratively until the best fit 
with the experimental $\mathrm{OH}$ profile was obtained (see Figure 1). The CHEMKIN-PRO software package ${ }^{38}$ was used to simulate $\mathrm{OH}$ time-histories using the constraints of constant energy and constant volume (constant UV). Experimentally determined rate coefficients for the reaction of DMC with $\mathrm{OH}$ radicals over the temperature range of $872-1295 \mathrm{~K}$ and $P \sim 1.5$ atm can be expressed by the following Arrhenius expression:

$k_{D M C+O H}=51.5 \times 10^{12} \exp \left(-\frac{2710}{T}\right) \mathrm{cm}^{3} \mathrm{~mol}^{-1} \mathrm{~s}^{-1}$

Measured rate coefficients for the reaction of $\mathrm{DMC}$ and $\mathrm{OH}$ radicals are compiled in Table 1 and plotted in Figure 3 along with the Lam et al. ${ }^{6}$ rate data for methyl esters $+\mathrm{OH}$.

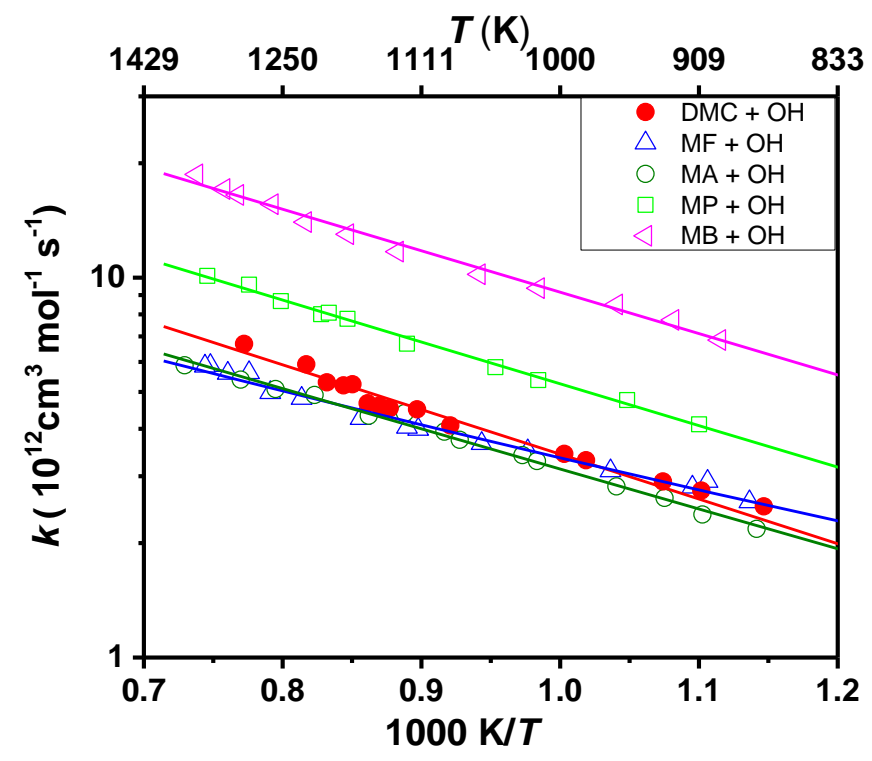

Figure 3: Symbols are experimental rate coefficients for the reaction of dimethyl carbonate (DMC), methyl formate (MF), methyl acetate (MA), methyl propanoate (MP), methyl butanoate (MB) with $\mathrm{OH}$ radicals. Closed circles: this work for $\mathrm{DMC}+\mathrm{OH}$; Open symbols: methyl esters + $\mathrm{OH}$ from Lam et al. ${ }^{6}$ Solid lines represent the total rate coefficients obtained from our site-specific rates using the $\mathrm{N}-\mathrm{N}-\mathrm{N}$ method (see text for details). 
Table 1: Experimental and theoretical rate coefficients for $\mathrm{H}$-abstraction reaction of DMC by $\mathrm{OH}$ radicals in the temperature range of 872-1295 K. Also compiled in Figure S1 (Supplementary Information).

\begin{tabular}{|c|c|c|c|c|c|}
\hline \multirow[t]{2}{*}{$P_{5}$} & \multirow[t]{2}{*}{$T_{5}$} & \multicolumn{2}{|c|}{$10^{-12} \times k_{\mathrm{DMC}+\mathrm{OH}}$} & \multirow[t]{3}{*}{$k_{\text {calc }} / k_{\text {expt'l }}$} & \multirow{3}{*}{$\begin{array}{c}\left|k_{\text {expt' } 1}-k_{\text {calc. }}\right| / k_{\text {expt' }}{ }^{\prime} \\
(\%)\end{array}$} \\
\hline & & $\begin{array}{c}\text { Experimental } \\
\left(\operatorname{expt}^{\prime} l\right)\end{array}$ & $\begin{array}{c}\text { Calculated }^{(a)} \\
\quad \text { (calc.) }\end{array}$ & & \\
\hline (atm) & (K) & \multicolumn{2}{|c|}{$\left(\mathrm{cm}^{3} \mathrm{~mol}^{-1} \mathrm{~s}^{-1}\right)$} & & \\
\hline 1.55 & 1185 & 5.20 & 6.50 & 1.25 & 24.98 \\
\hline 1.60 & 1150 & 4.60 & 5.89 & 1.28 & 28.15 \\
\hline 1.90 & 1140 & 4.53 & 5.73 & 1.26 & 26.50 \\
\hline 1.80 & 1086 & 4.08 & 4.89 & 1.20 & 19.94 \\
\hline 1.87 & 982 & 3.31 & 3.55 & 1.07 & 7.30 \\
\hline 2.10 & 931 & 2.91 & 3.00 & 1.03 & 3.20 \\
\hline 2.30 & 908 & 2.75 & 2.78 & 1.01 & 1.08 \\
\hline 1.83 & 872 & 2.50 & 2.45 & 0.98 & 1.80 \\
\hline 1.60 & 1202 & 5.30 & 6.81 & 1.29 & 28.53 \\
\hline 1.42 & 1161 & 4.67 & 6.08 & 1.30 & 30.13 \\
\hline 1.62 & 1295 & 6.69 & 8.69 & 1.30 & 29.82 \\
\hline 1.43 & 1176 & 5.24 & 6.34 & 1.21 & 20.92 \\
\hline 1.47 & 1224 & 5.91 & 7.22 & 1.22 & 22.19 \\
\hline 1.87 & 1115 & 4.50 & 5.33 & 1.18 & 18.49 \\
\hline 1.74 & 997 & 3.44 & 3.73 & 1.08 & 8.33 \\
\hline
\end{tabular}

${ }^{(a)}$ Stochastic approach with $10^{7}$ numbers of trials.

As speculated, the reaction of $\mathrm{OH}$ radicals with methyl butanoate (MB) showed the highest reactivity followed by methyl propanoate (MP) due to the presence of secondary hydrogen atoms. 
Interestingly, dimethyl carbonate (DMC), methyl formate (MF) and methyl acetate (MA) exhibited similar reactivity with $\mathrm{OH}$ radicals under our experimental conditions. This observation clearly indicates that the primary $\mathrm{C}-\mathrm{H}$ bonds adjacent either to $\mathrm{C}=\mathrm{O}$ or to ether oxygen contribute equally to the overall rate of methyl esters and $\mathrm{OH}$ reactions; these hydrogen atom sites are named as

$\alpha^{\prime}\left(1^{\circ}\right)$ and $\alpha\left(1^{\circ}\right)$, respectively, in Section 4.3. Similar observations were made by Mendes et al. ${ }^{39}$ in their recent theoretical work for hydrogen abstraction reactions of some esters with $\mathrm{OH}$ radicals. They found that the bond dissociation energies (BDEs) of primary $\mathrm{C}-\mathrm{H}$ bonds at $\alpha^{\prime}\left(1^{\circ}\right)$ and $\alpha\left(1^{\circ}\right)$ sites of esters are similar ( $408 \mathrm{~kJ} / \mathrm{mol})$. However, they calculated the energy barrier for hydrogen abstraction at the $\alpha^{\prime}\left(1^{\circ}\right)$ position to be about $\sim 12 \mathrm{~kJ} / \mathrm{mol}$ higher than those from the $\alpha\left(1^{\circ}\right)$ site of methyl esters. Nonetheless, they found the reactivity of these hydrogen atoms for methyl acetate to be similar at high temperatures. Hydrogen atom adjacent to the carbonyl group of methyl formate was found to react roughly three times faster than that of the $\mathrm{C}-\mathrm{H}$ adjacent to the ether oxygen under the conditions of our experiments.

\subsection{Potential energy surface and rate coefficient calculations for $\mathrm{DMC}+\mathrm{OH}$ reaction}

Potential energy surface for the reaction of DMC with $\mathrm{OH}$ radicals was mapped out at the $\operatorname{CCSD}(\mathrm{T}) / \mathrm{cc}-\mathrm{pV}(\mathrm{D}, \mathrm{T}) \mathrm{Z} / / \mathrm{MP} 2 /$ aug-cc-pVDZ level of theory. The results are displayed in Figure 4 and Figure S2 of the Supplementary Information. 


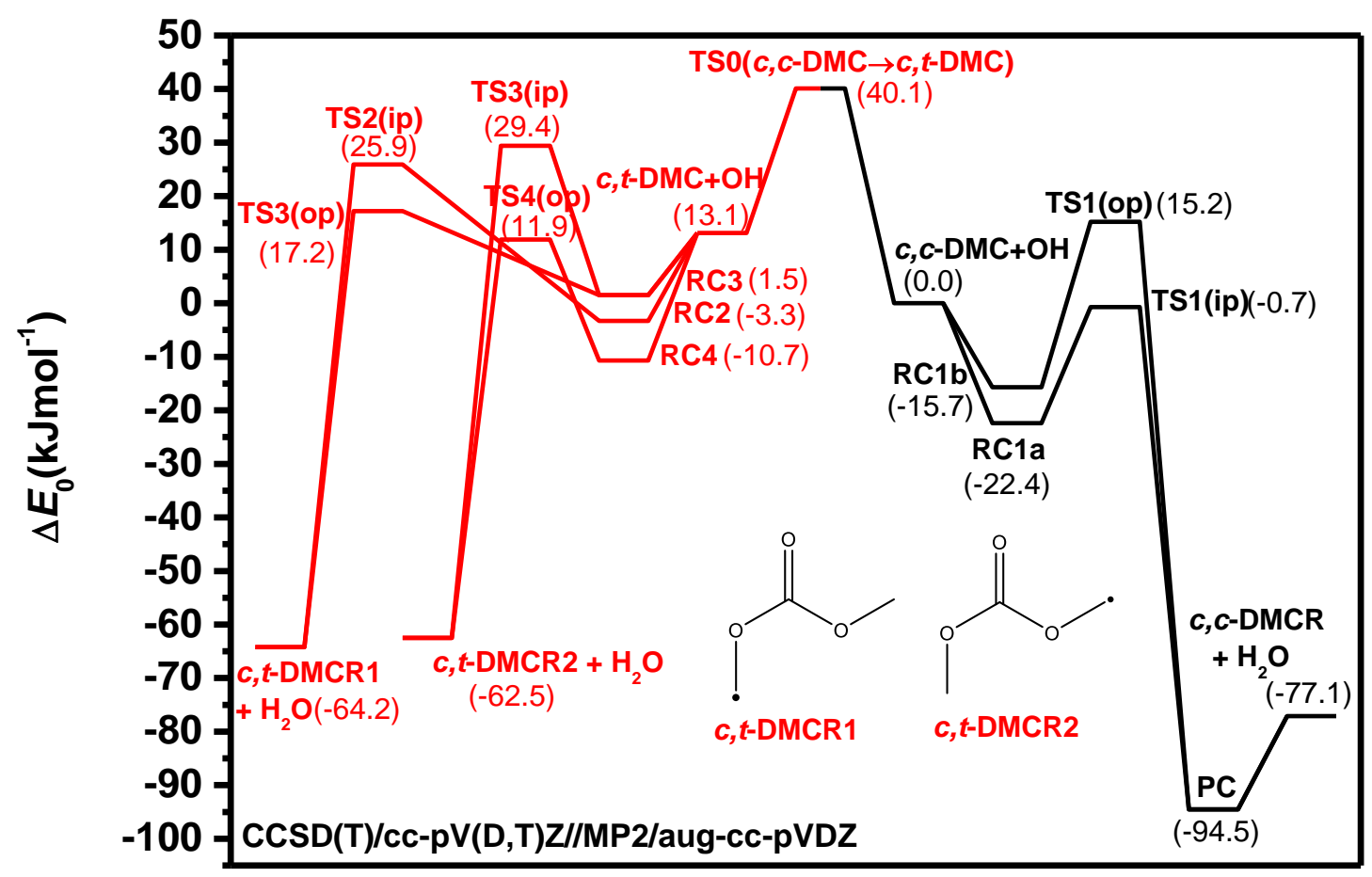

Reaction coordinate

Figure 4: Zero-point corrected relative energy of the $\mathrm{DMC}+\mathrm{OH}$ reaction system. Relative energies are obtained at the $\operatorname{CCSD}(\mathrm{T}) / \mathrm{cc}-\mathrm{pV}(\mathrm{D}, \mathrm{T}) \mathrm{Z} / \mathrm{MP} 2 /$ aug-cc-pVDZ level of theory.

Among the four conformers of DMC, only two (cis-cis (c,c-DMC) and cis-trans (c,t-DMC)) are shown because the two remaining conformers, namely near-trans-near-trans (nt,nt-DMC) and trans-near-trans (t,nt-DMC) lie significantly higher in energy (66.7 and $72.3 \mathrm{~kJ} / \mathrm{mol}$, respectively) 40 than the most stable $c, c$-DMC conformer. We calculated the relative energy of $c, t$-DMC conformer to be $13.1 \mathrm{~kJ} / \mathrm{mol}$ higher than the $c, c$-DMC conformer which is in line with the values obtained by Reddy et $a l^{40}$ at MP2/aug-ccpVQZ level of theory. The relative population of the trans-trans type DMC conformers even at $1000 \mathrm{~K}$ was found to be negligible. Therefore, their significance to the $\mathrm{H}$-atom abstraction reaction of $\mathrm{DMC}$ by $\mathrm{OH}$ radicals is kinetically irrelevant. As for $c, t$-DMC conformer, its relative population may be high enough to contribute significantly to the kinetics of $\mathrm{DMC}+\mathrm{OH}$ reaction as the conformational change $(c, c-\mathrm{DMC} \rightarrow c, t-\mathrm{DMC})$ is attainable via TS0 with a modest energy barrier of $40 \mathrm{~kJ} / \mathrm{mol}$ (see Figure 4). Our estimate suggests 
that a significant amount of DMC, as high as $\sim 20 \%$, exists as $c, t$-DMC conformer at $1000 \mathrm{~K}$. Therefore, the two low lying conformers of DMC, i.e., $c, c$-DMC and $c, t$-DMC, should be considered for theoretical kinetic analysis.

Similar to the reactions of other oxygenated organic molecules and $\mathrm{OH}$ radicals ${ }^{39,41-45}$, the abstraction of $\mathrm{H}$ atoms from $\mathrm{DMC}$ by $\mathrm{OH}$ radicals occurs via addition elimination mechanism in an overall exothermic process (see Figure 4). For these reactions, the first elementary step is the formation of hydrogen-bonded reactant complex (RC). For DMC $+\mathrm{OH}$ reaction, all possible reaction complexes for the two low-lying DMC conformers, i.e., $c, c$-DMC and $c, t$-DMC, were explored. Starting with $c, c$-DMC $+\mathrm{OH}$ reaction, the interaction of $\mathrm{OH}$ radicals with $c, c-\mathrm{DMC}$ results into the formation of two hydrogen bonded pre-reaction complexes. These pre-reaction complexes, $\mathrm{RC} 1 \mathrm{a}$ and $\mathrm{RC} 1 \mathrm{~b}$, are formed when $\mathrm{OH}$ dipole vector orients towards $c, c$-DMC, as shown by the directions 1 and 2 in Figure 5, respectively.

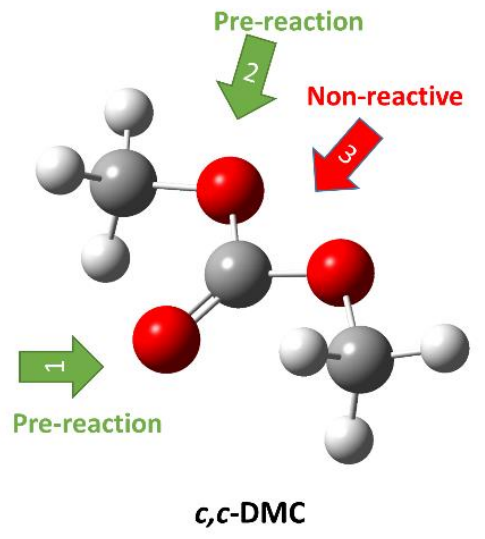

$(0.0)$

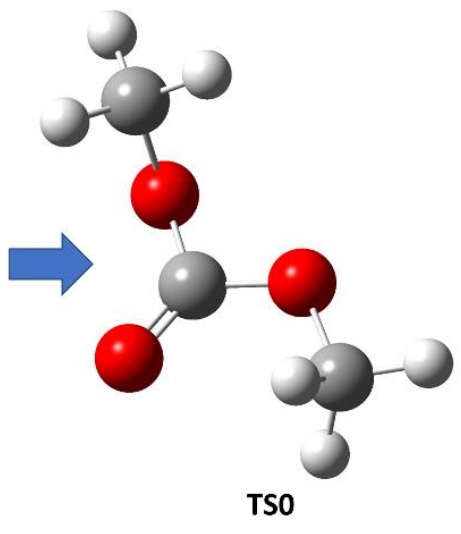

(40.1)

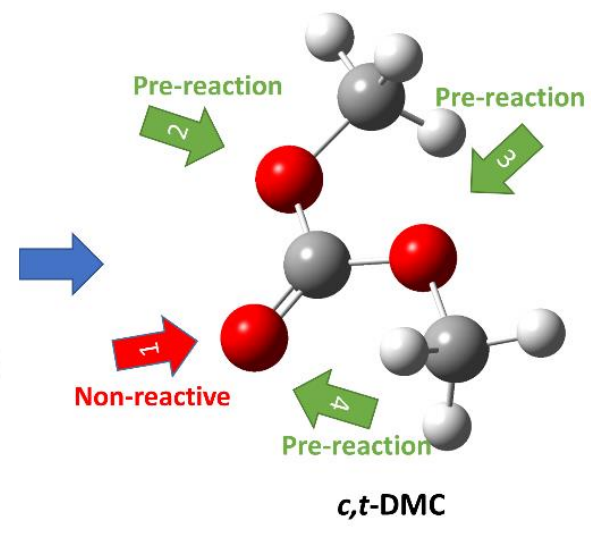

(13.1)

Figure 5: Structures along the conformational change with kinetic relevance and schematic representation of the molecular complex of $\mathrm{OH}$ and DMC indicating the orientation of the pre-reaction complexes. Zero- 
point corrected energies are obtained at the $\operatorname{CCSD}(\mathrm{T}) / \mathrm{cc}-\mathrm{pV}(\mathrm{D}, \mathrm{T}) \mathrm{Z} / \mathrm{MP} 2 / \mathrm{aug}-\mathrm{cc}-\mathrm{pVDZ}$ level of theory. Relative energies in the parentheses are in units of $\mathrm{kJ} / \mathrm{mol}$.

The formation of hydrogen bond between $\mathrm{H}$ atom of $\mathrm{OH}$ radical and oxygen atom of the carbonyl group of $c, c$-DMC results in RC1a complex which has an energy of about $22.4 \mathrm{~kJ} / \mathrm{mol}$ lower than the reactants. This complex is found to be 18.4 and $25.1 \mathrm{~kJ} / \mathrm{mol}$ more stable than the reactants at B3LYP geometry based CBS-QB3 and G4 methods, respectively. However, we could not locate this complex (RC1a) at CBS-APNO and G3 levels of theory. This may be due to missing dispersion interaction energy term in Hartee-Fock (HF) method which is the first geometry optimization step for both CBS-APNO and G3 methods. The stabilization energy of this prereaction complex (RC1a) compares very well to that of the corresponding complex found in similar methyl esters $+\mathrm{OH}$ reaction systems. For instance, the value of the stabilization energy was found to be $20.5 \mathrm{~kJ} / \mathrm{mol}^{46}$ and $21.5 \mathrm{~kJ} / \mathrm{mol}^{39}$ for methyl acetate $+\mathrm{OH}$ reaction using CCSD(T)/CBS and G3 levels of theory, respectively, and $\sim 22 \mathrm{~kJ} / \mathrm{mol}$ at the $\mathrm{G} 3$ level of theory for methyl propionate/methyl butanoate $+\mathrm{OH}$ reaction. ${ }^{39}$ As for $\mathrm{RC} 1 \mathrm{~b}$ pre-reaction complex, it is formed by the interaction of $\mathrm{OH}$ radical with ether oxygen of $c, c$-DMC forms. The stabilization energy of $\mathrm{RC} 1 \mathrm{~b}$ is found to be $15.7 \mathrm{~kJ} / \mathrm{mol}$ at $\mathrm{CCSD}(\mathrm{T}) / \mathrm{cc}-\mathrm{p}(\mathrm{D}, \mathrm{T}) \mathrm{Z} / \mathrm{MP} 2 /$ aug-cc-pVDZ level of theory. The formation of pre-reaction complex similar to $\mathrm{RC} 1 \mathrm{~b}$ has not been reported earlier for methyl esters + OH reactions..$^{39,46}$

Our intrinsic reaction coordinate (IRC) calculations revealed that RC1a complex proceeds via inplane H-abstraction transition state (TS1(ip) with $\Delta E_{0}=-0.7 \mathrm{~kJ} / \mathrm{mol}$ ), whereas RC1b exits through out of plane transition state TS1(op) with $\Delta E_{0}=15.2 \mathrm{~kJ} / \mathrm{mol}$ relative to the reactant (see Figure 4 ). Due to the presence of two hydrogen bonds, both transition states are non-linear with the O-H-C bond angle being $163.8^{\circ}$ and $163.2^{\circ}$ for TS1(op) and TS1(ip), respectively, as shown in Figure 6. 


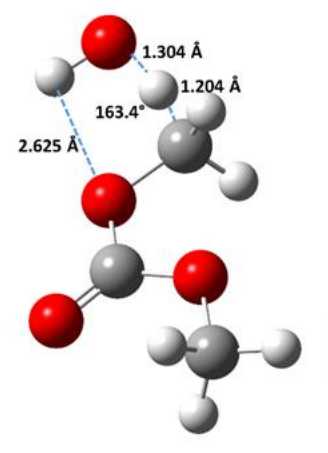

TS2(ip)

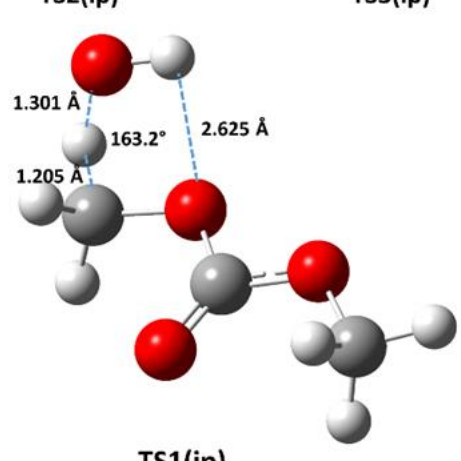

TS1(ip)

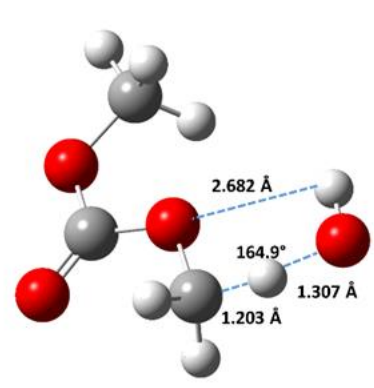

TS3(ip)

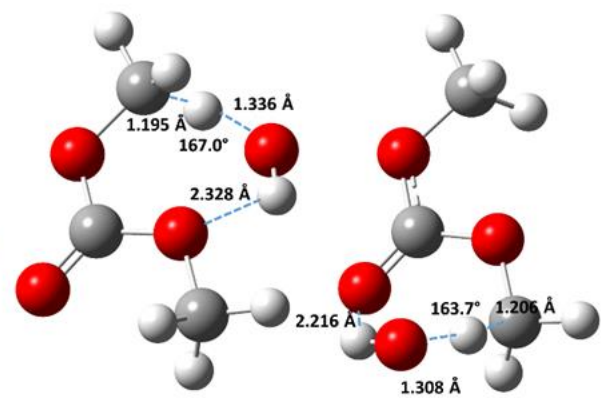

TS3(op)

TS4(op)

Figure 6: MP2/aug-cc-pVDZ transition state geometries for the $\mathrm{H}$-abstraction reaction of DMC by $\mathrm{OH}$ radical.

Relative energy of TS1(ip) is almost thermo-neutral compared to the un-complexed reactants which is similar to that seen in the $\mathrm{H}$-abstraction from the $-\mathrm{OCH}_{3}$ moiety of methyl esters by $\mathrm{OH}$ radicals. As seen in Error! Reference source not found., CBS-QB3, CBS-APNO, G3 and G4 methods predict the relative energy of the TS(ip) to be $0.2,-6.5,3.8$ and $0.5 \mathrm{~kJ} / \mathrm{mol}$, respectively.

Table 2: Zero-point corrected relative energies in $\mathrm{kJ} / \mathrm{mol}$ for $c, c-\mathrm{DMC}+\mathrm{OH}$ reaction system calculated at different levels of theory at $0 \mathrm{~K}$. Only the species involved for the most favorable path are considered here.

\begin{tabular}{lccccc}
\hline \multicolumn{1}{c}{ Method } & $c, c-\mathrm{DMC}+\mathrm{OH}$ & $\mathrm{RC1a}$ & $\mathrm{TS} 1(\mathrm{ip})$ & $\mathrm{PC}$ & $c, c-\mathrm{DMCR}+\mathrm{H}_{2} \mathrm{O}$ \\
\hline $\mathrm{CCSD}(\mathrm{T}) / \mathrm{cc}-\mathrm{pV}(\mathrm{D}, \mathrm{T}) \mathrm{Z}$ & $\mathbf{0 . 0}$ & $\mathbf{- 2 2 . 4}$ & $\mathbf{- 0 . 7}$ & $\mathbf{- 9 4 . 5}$ & $\mathbf{- 7 7 . 1}$ \\
//MP2/aug-cc-pVDZ & 0.0 & -18.4 & 0.2 & -91.8 & -78.7 \\
CBS-QB3 & & & & &
\end{tabular}




\begin{tabular}{lccccc} 
CBS-APNO & 0.0 & - & -6.5 & -91.9 & -77.6 \\
G3 & 0.0 & - & 3.8 & -90.7 & -74.8 \\
G4 & 0.0 & -25.1 & 0.5 & -96.7 & -82.8 \\
\hline
\end{tabular}

Energy difference of the TS1(ip) among various methods is quite small. The largest deviation of $5.8 \mathrm{~kJ} / \mathrm{mol}$ compared to $\mathrm{CCSD}(\mathrm{T}) / \mathrm{CBS}$ method was obtained at CBS-QB3 level of theory. Relative energy of the TS1(op) lies significantly higher $(15.2 \mathrm{~kJ} / \mathrm{mol})$ than the reactant. Therefore, the hydrogen abstraction of $c, c$-DMC by $\mathrm{OH}$ radicals via $\mathrm{TS} 1$ (op) is kinetically unfavorable channel. Both TSs are linked to the same product complex (PC) which lies deep into an energy well 94.5 $\mathrm{kJ} / \mathrm{mol}$ below the reactants. Because the product complex carries high internal energy and its subsequent reaction is a barrierless process with a threshold energy of $17.4 \mathrm{~kJ} / \mathrm{mol}$ only, this complex rapidly dissociates to yield water and dimethyl carbonate radical in an overall exothermic process $\left(\Delta_{\mathrm{r}, 298.15 \mathrm{~K}} H^{0}=-75.8 \mathrm{~kJ} / \mathrm{mol}\right)$. Therefore, the product complex has no kinetic relevance along the reaction sequence: $c, c$-DMC $\rightarrow \mathrm{RC} 1 \mathrm{a}$ or $\mathrm{RC} 1 \mathrm{~b} \rightarrow \mathrm{TS}(\mathrm{ip})$ or $\mathrm{TS}(\mathrm{op}) \rightarrow \mathrm{PC} \rightarrow c, c$-DMCR $+\mathrm{H}_{2} \mathrm{O}$ (see also Figure $\mathrm{S} 3$ of the Supplementary Information).

Besides this reaction path, we found an additional channel where $\mathrm{OH}$ radical attacks the carbonyl group of $c, c$-DMC to eventually produce methyl hydrogen carbonate $\left(\mathrm{CH}_{3} \mathrm{OC}(=\mathrm{O}) \mathrm{OH}\right)$ and methoxy radical $\left(\mathrm{OCH}_{3}\right)$. According to the CBS-QB3 method, this substitution reaction occurs in an overall exothermic process $\left(\Delta_{\mathrm{r}, 0 \mathrm{~K}} H^{0}=-34.9 \mathrm{~kJ} / \mathrm{mol}\right)$ via a tight transition state with an energy barrier of $110.3 \mathrm{~kJ} / \mathrm{mol}$. Due to this high energy barrier, its contribution to the total rate of DMC $+\mathrm{OH}$ reaction can safely be neglected. 
The discussion above infers that the reaction of $c, c$-DMC conformer with $\mathrm{OH}$ radicals forming RC1a and eventually leading to products via TS1(ip) is the energetically favorable path. Collision stabilization of the pre-reaction complex RC1a is inefficient due to the shallow nature of the well and high temperature of this study. Therefore, the chemically activated pre-reaction complex dissociates rapidly back to the reactant as the exit channel has an energy barrier of $21.7 \mathrm{~kJ} / \mathrm{mol}$ and involves a tight transition state. The hydrogen abstraction reaction of $c, c$-DMC by $\mathrm{OH}$ radicals consists of reversible formation of pre-reaction complex before water can depart to produce $c, c$ DMCR.

As for $c, t$-DMC $+\mathrm{OH}$ reaction, we identified three hydrogen bonded pre-reaction complexes namely RC2, RC3 and RC4 (see Figure 4). The appearance of an additional pre-reaction complex can be understood from the fact that $c$, $t$-DMC is less symmetric $\left(\mathrm{C}_{\mathrm{s}}\right)$ than $c, c$-DMC $\left(\mathrm{C}_{2 \mathrm{v}}\right)$. Therefore, the two orientations of $\mathrm{OH}$ towards ether oxygens of $c, t$-DMC are distinguishable and hence give rise to two different pre-reaction complexes (RC2 and RC3). Among these complexes, RC4 is found to be most stable complex which lies about $23.8 \mathrm{~kJ} / \mathrm{mol}$ below un-complexed reactants (c,t-DMC and $\mathrm{OH}$ radicals). This complex is formed through hydrogen bonding of approaching $\mathrm{OH}$ radical with the oxygen atom of the carbonyl group of $c$, $t$-DMC. The other two complexes (RC2 and $\mathrm{RC} 3$ ) are formed when incoming $\mathrm{OH}$ radical orients towards ether oxygen of $c, t$-DMC conformer, as shown in Figure 5. As can be seen in Figure 4, RC2 is more stable than $\mathrm{RC} 3$ by $4.8 \mathrm{~kJ} / \mathrm{mol}$. Since all these complexes occupy a shallow well $(23.8 \mathrm{~kJ} / \mathrm{mol}$ being the deepest), collisional stabilization at these wells is inefficient. Hence, these will dissociate back almost instantly as their exit barriers are high and the corresponding transition states are tight. The structures of the transition states are provided in Figure 6. As can be seen in Figure 4, the Habstraction reaction of $c, t-\mathrm{DMC}$ and $\mathrm{OH}$ radicals occurring via TS2(ip), that links $\mathrm{RC} 2$ to the 
products $\left(c, t\right.$-DMCR1 and $\left.\mathrm{H}_{2} \mathrm{O}\right)$, is not energetically favored due to its relatively high energy barrier. Similar arguments can be made for the reaction occurring via the sequence $c, t$-DMC $+\mathrm{OH}$ $\rightarrow \mathrm{RC} 3 \rightarrow \mathrm{TS} 3$ (ip) $\rightarrow c, t$-DMCR2 $+\mathrm{H}_{2} \mathrm{O}$. However, the reaction channel that takes $\mathrm{RC} 3$ to the products ( $c$, t-DMCR2 and $\mathrm{H}_{2} \mathrm{O}$ ) via transition state TS3(op) is kinetically important as TS3(op) lies only $4.1 \mathrm{~kJ} / \mathrm{mol}$ higher than the reactants $(c, t-\mathrm{DMC}+\mathrm{OH})$. The relative energy of this transition state (TS3(op)) is found to be significantly lower than TS3(ip) due to less ring constraint and stronger hydrogen bond. In the TS structures, the $\mathrm{O} \cdots \mathrm{H}$ distance is found to be much shorter in TS3(op) $\left(r_{\mathrm{O}} \ldots \mathrm{H}=2.328 \AA\right)$ than that of TS3(ip) $\left(r_{\mathrm{O}} \ldots \mathrm{H}=2.682 \AA\right)$. The lowest lying transition state TS4(op) originates from pre-reaction complex RC4 leading to $c$, $t$-DMC and $\mathrm{H}_{2} \mathrm{O}$ as products. As TS4(op) is submerged below the reactants by $1.2 \mathrm{~kJ} / \mathrm{mol}$ due to the short hydrogen bond $\left(r_{\mathrm{O}} \ldots \mathrm{H}\right.$ $=2.216 \AA$ ), it plays an important role in the kinetics of $c, t$-DMC and $\mathrm{OH}$ reaction. As seen in Figure 4, depending on the type of $\mathrm{H}$ atom being abstracted, the products of $c, t-\mathrm{DMC}$ and $\mathrm{OH}$ reaction can be different with less energy release for $c, t$-DMCR2 product radical.

Unless stated otherwise, the energy values discussed above are taken from $\operatorname{CCSD}(\mathrm{T}) / \mathrm{cc}-$ $\mathrm{pV}(\mathrm{D}, \mathrm{T}) \mathrm{Z} / \mathrm{MP} 2 /$ aug-cc-pVDZ level of theory. However, single points calculations for the stationary points of the most favorable channel, i.e., cc-DMC $+\mathrm{OH} \rightarrow \mathrm{RC1a} \rightarrow \mathrm{TS} 1$ (ip) $\rightarrow \mathrm{PC} \rightarrow$ $c, c$-DMCR $+\mathrm{H} 2 \mathrm{O}$ were also performed at the CBS-QB3, CBS-APNO, G3 and G4 levels of theory for reliability check. The results are listed in Error! Reference source not found. for comparison. As can be seen, the relative energy values obtained at various levels of theory are method independent as these matched very well with an acceptable uncertainty range. Our earlier works ${ }^{41,47}$ have shown that $\mathrm{CCSD}(\mathrm{T}) / \mathrm{cc}-\mathrm{pV}(\mathrm{D}, \mathrm{T}) \mathrm{Z} / \mathrm{MP} 2 /$ aug-cc-pVDZ level of theory provides an accurate picture of the energetics for similar systems. Therefore, we have only employed energetic profiles from CCSD(T)/CBS calculations and the geometry/frequency information from 
the MP2/aug-cc-pVDZ level of theory for kinetic analyses. The geometry, rotational constants and the vibrational frequencies obtained at the MP2/aug-cc-pVDZ level of theory are listed in Table S1 (Supplementary Information).

Temperature- and pressure -dependent rate coefficients were obtained by employing ab initio ME/RRKM calculations. For master equation calculations, the single exponential-down model was used for collisional energy transfer with an average energy transfer per "downward" collision $\left(<\Delta E_{\text {down }}>\right.$ ) of $250.0 \mathrm{~cm}^{-1}$ for argon as a bath gas. Lennard-Jones (L-J) parameters employed in the calculation are: for Ar: $\varepsilon / \mathrm{kB}=93.3 \mathrm{~K}, \sigma=3.542 \AA^{48}$ and for the well depth $\mathrm{PC}\left(\mathrm{C}_{3} \mathrm{H}_{7} \mathrm{O}_{4}\right), \varepsilon / \mathrm{k}_{\mathrm{B}}=$ $669.8 \mathrm{~K}, \sigma=5.94 \AA$, estimated from $\mathrm{C}_{3} \mathrm{H}_{5} \mathrm{O}_{4}{ }^{49}$. In rate constant calculations, the most table conformer, cis,cis-DMC, was explicitly considered as the reactant while the cis,trans conformer was implicitly included in the calculations through the hindered internal rotation treatment (cf. the hindrance potential for the cis,cis-DMC given in Table S2(a) where the cis,trans conformer is at the dihedral angle of zero degree). Same procedure was applied for the transition states (see Table S2). Table 2 lists the species involved for the most favorable path which was explicitly included in the rate constant calculations. Calculated rate coefficients are plotted in Figure S4 (Supplementary Information) and compiled in the Table 1 to compare with the experimental values. As can be seen, the computed rate coefficients are in excellent agreement with the experimental data with an average absolute deviation of $18.1 \%$. It is worth noting that there was no adjustment made to the $a b$ initio calculations (e.g., the barrier height adjustment). The calculated values of the rate coefficients for $P=1.5$ atm and $T=300-1500 \mathrm{~K}$ may be expressed as:

$$
k_{D M C+O H}^{\text {calc. }}(T)=3.96 \times 10^{-3}\left(\frac{T}{K}\right)^{4.47} \exp \left(\frac{1316}{T}\right) \quad \mathrm{cm}^{3} \mathrm{~mol}^{-1} \mathrm{~s}^{-1}
$$




\subsection{Site-specific rate coefficient derivations for methyl esters $+\mathrm{OH}$ reactions}

The knowledge of the reaction kinetics for $\mathrm{DMC}+\mathrm{OH}$ reaction is further utilized to deduce the site-specific hydrogen abstraction rate coefficients for straight chain methyl esters and $\mathrm{OH}$ reactions using the Next-Nearest-Neighbour (N-N-N) method. ${ }^{7,}{ }^{50}$ In methyl esters $+\mathrm{OH}$ reaction systems, the type of abstractable hydrogen atoms varies from two to several depending on the type of methyl esters. For example, the simplest methyl ester is methyl formate (MF) which offers two types of $\mathrm{H}$ atoms to be abstracted, i.e., one type of $\mathrm{H}$ atom, $\alpha^{\prime}(0)$, that is adjacent to the carbonyl group and the other, $\alpha(1)$, in the methyl group adjacent to the ether oxygen. Similarly, four different types of hydrogen atoms, namely $\alpha\left(1^{\circ}\right), \alpha^{\prime}\left(2^{\circ}\right), \beta^{\prime}\left(2^{\circ}\right)$ and $\gamma^{\prime}\left(1^{\circ}\right)$ are present in methyl butanoate $(\mathrm{MB})$. This is the largest straight chain methyl ester considered in the current study because the abstraction of $\mathrm{H}$ atom beyond the $\gamma^{\prime}$ site would have similar reactivity to that found in straight chain alkanes. For example, the abstraction of $\gamma^{\prime}\left(1^{\circ}\right)$ hydrogen atom from methyl butanoate was found to have approximately the same rate as the abstraction of primary hydrogen atom from alkanes. ${ }^{39}$ The nomenclature for the type of hydrogen atoms, shown in Figure 7, in the esters considered here is adopted from a recent theoretical work of Mendes et al. ${ }^{39}$ 

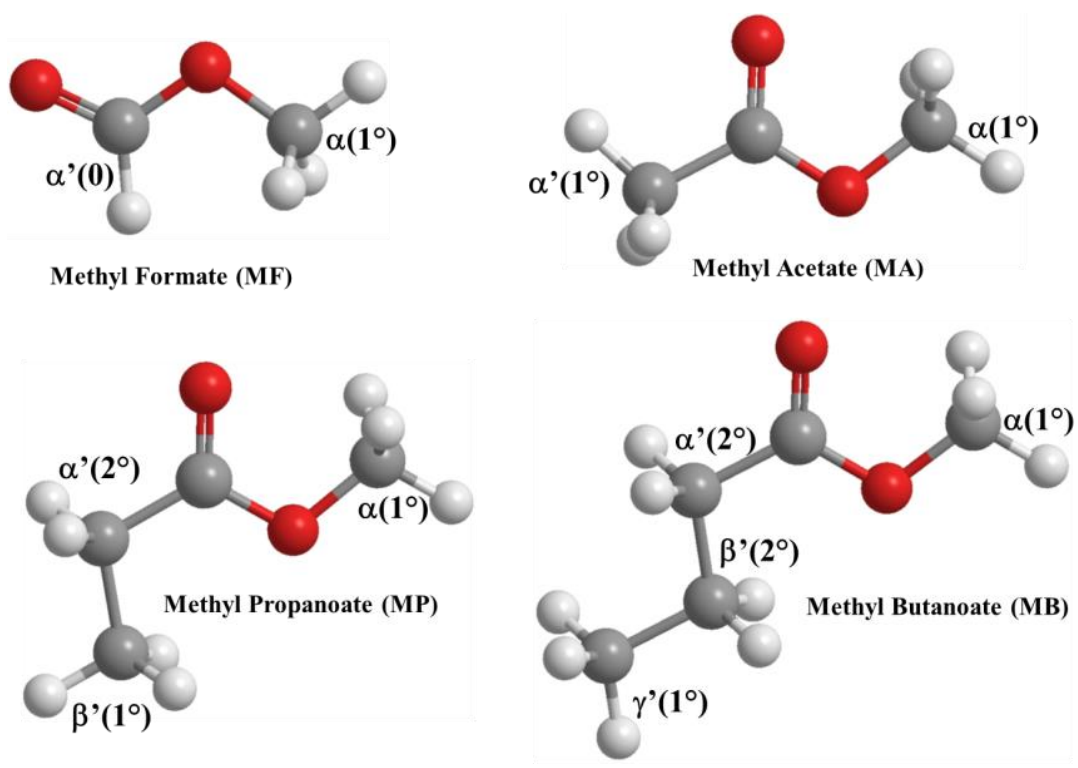

Figure 7: Nomenclature for the abstractable hydrogens present in straight chain methyl esters.

Experimental data for the reactions of four small straight chain methyl esters, methyl butanoate (MB), methyl propanoate (MP), methyl acetate (MA) and methyl formate (MF), with $\mathrm{OH}$ radicals are taken from Lam et al. ${ }^{6}$ Overall rate coefficients in unit of $\mathrm{cm}^{3} \mathrm{~mol}^{-1} \mathrm{~s}^{-1}$ for these methyl esters and $\mathrm{OH}$ radical reactions can be written as the sum of various site-specific rate coefficients:

$$
\begin{aligned}
& k_{M F+O H}(T)=3 \alpha\left(1^{\circ}\right)+\alpha^{\prime}\left(0^{\circ}\right)=2.56 \times 10^{13} \exp \left(-\frac{2026}{T}\right) \\
& k_{M A+O H}(T)=3 \alpha\left(1^{\circ}\right)+3 \alpha^{\prime}\left(1^{\circ}\right)=3.59 \times 10^{13} \exp \left(-\frac{2438}{T}\right) \\
& k_{M P+O H}(T)=3 \alpha\left(1^{\circ}\right)+2 \alpha^{\prime}\left(2^{\circ}\right)+3 \beta^{\prime}\left(1^{\circ}\right)=6.65 \times 10^{13} \exp \left(-\frac{2539}{T}\right) \\
& k_{M B+O H}(T)=3 \alpha\left(1^{\circ}\right)+2 \alpha^{\prime}\left(2^{\circ}\right)+2 \beta^{\prime}\left(2^{\circ}\right)+3 \gamma^{\prime}\left(1^{\circ}\right)=1.13 \times 10^{14} \exp \left(-\frac{2515}{T}\right)
\end{aligned}
$$

This set of 4 linear independent equations has 6 unknowns: $\alpha\left(1^{\circ}\right), \alpha^{\prime}\left(0^{\circ}\right), \alpha^{\prime}\left(1^{\circ}\right), \alpha^{\prime}\left(2^{\circ}\right), \beta^{\prime}\left(1^{\circ}\right)$ and $\beta^{\prime}\left(2^{\circ}\right)$. Here, $\gamma^{\prime}\left(1^{\circ}\right)$ is taken equal to the primary hydrogen atom abstraction rate from alkanes. ${ }^{50}$ Therefore, two additional equations are needed to fully solve this system of linear equations. As 
stated earlier, the abstraction of $\alpha\left(1^{\circ}\right)$ at the $-\mathrm{OCH}_{3}$ moiety of various methyl esters showed similar reactivity. ${ }^{39}$ Using a structural analogy, we may argue that all hydrogen atoms present in $c, c-\mathrm{DMC}\left(\mathrm{CH}_{3} \mathrm{OC}(\mathrm{O}) \mathrm{OCH}_{3}\right)$ are equivalent and react with equal rates as the hydrogen abstraction rate of $\alpha\left(1^{\circ}\right)$ in methyl esters $+\mathrm{OH}$ reactions. This allows us to construct one additional equation, where the Arrhenius expression is obtained from our experimental work:

$k_{D M C+O H}(T)=6 \alpha\left(1^{\circ}\right)=51.5 \times 10^{12} \exp \left(-\frac{2710}{T}\right) \quad \mathrm{cm}^{3} \mathrm{~mol}^{-1} \mathrm{~s}^{-1}$

For the second needed relation, we construct an equation (11) where the calculated site-specific rate coefficients were obtained from Mendes et al. ${ }^{39}$ for methyl propanoate (MP) + OH reaction. For $\mathrm{MP}+\mathrm{OH}$ reaction, we note that the calculated values for the total rates were found to be about $50 \%$ slower than the experimental measurement of Lam et $a l .{ }^{6}$, however, the temperature dependence of the rate coefficients was captured adequately. Due to this reason, we used the ratio of the theoretical estimates as:

$\left[\frac{2 \alpha^{\prime}\left(2^{\circ}\right)}{2 \alpha^{\prime}\left(2^{\circ}\right)+3 * \beta^{\prime}\left(1^{\circ}\right)}\right]_{\text {exptıl }}=\left[\frac{2 \alpha^{\prime}\left(2^{\circ}\right)}{2 \alpha^{\prime}\left(2^{\circ}\right)+3 * \beta^{\prime}\left(1^{\circ}\right)}\right]_{\text {calc } .}$

The six equations listed above, Eqs. (6) - (11), may be solved to extract site-specific H-abstraction rate coefficients for straight chain methyl esters $+\mathrm{OH}$ reactions. An optimization method explained elsewhere ${ }^{34}$ is adopted here to extract the six unknowns. The results of our calculations are plotted in Figure 8 and compiled in Table 1. 


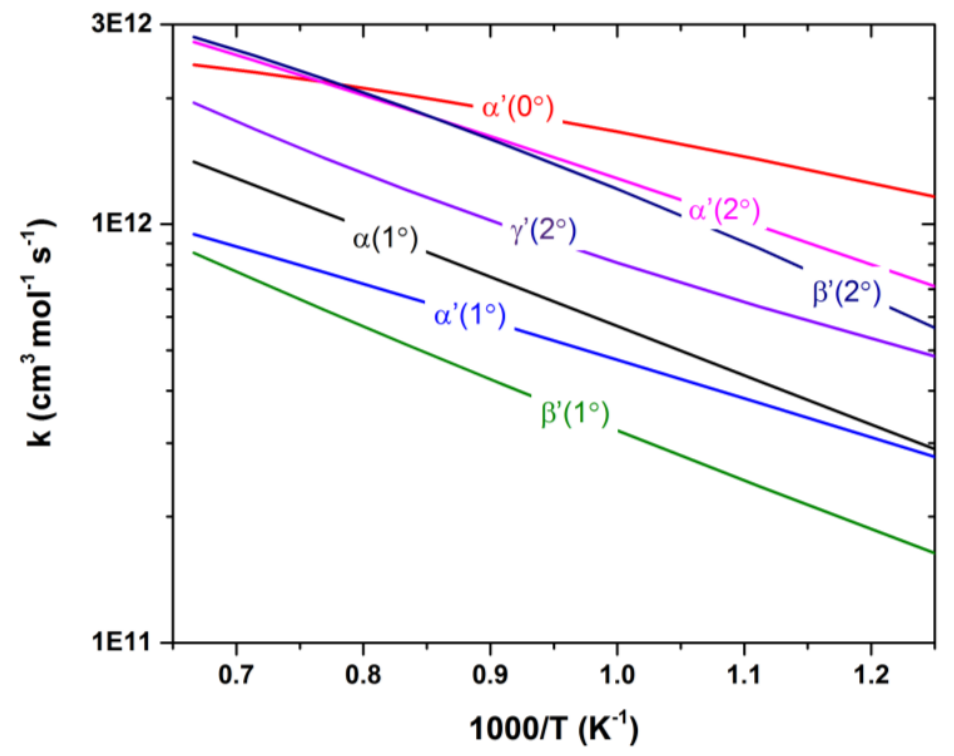

Figure 8: Calculated site-specific $\mathrm{H}$-abstraction rate coefficient per $\mathrm{H}$-atom of methyl esters $+\mathrm{OH}$ reactions.

Table 1: Arrhenius Parameters for the site-specific rates per $\mathrm{H}$ atom for methyl esters $+\mathrm{OH}$ reaction. These parameters are valid over 800 to $1350 \mathrm{~K}$.

\begin{tabular}{|c|c|c|}
\hline \multirow[t]{2}{*}{ per C-H site of methyl esters } & \multicolumn{2}{|c|}{ Arrhenius Parameters } \\
\hline & $A /\left(10^{12} \mathrm{~cm}^{3} \mathrm{~mol}^{-1} \mathrm{~s}^{-1}\right)$ & $E_{\mathrm{a}} / \mathbf{R}(\mathbf{K})$ \\
\hline$\alpha(1)$ & 8.59 & 2710.3 \\
\hline$\alpha^{\prime}(0)$ & 5.46 & 1202.3 \\
\hline$\alpha^{\prime}(1)$ & 3.81 & 2085.0 \\
\hline$\alpha^{\prime}(2)$ & 12.5 & 2273.3 \\
\hline$\beta^{\prime}(1)$ & 5.88 & 2905.7 \\
\hline$\beta^{\prime}(2)$ & 16.0 & 2583.7 \\
\hline$\gamma^{\prime}(1)$ & 10.5 & 2554.0 \\
\hline
\end{tabular}

As expected, site-specific rate coefficients for the secondary sites $\left(2^{\circ}\right)$ are larger than the primary sites $\left(1^{\circ}\right)$ for a given chemical environment. In other words, $\alpha^{\prime}\left(2^{\circ}\right)$ and $\beta^{\prime}\left(2^{\circ}\right)$ hydrogen atoms have higher reactivity than $\alpha^{\prime}\left(1^{\circ}\right)$ and $\beta^{\prime}\left(1^{\circ}\right)$, respectively. Not surprisingly, hydrogen atoms at 
the $\alpha\left(1^{\circ}\right)$ and $\alpha^{\prime}\left(1^{\circ}\right)$ positions are found to have similar reactivity over the temperature range of our study. This explains why both methyl acetate and dimethyl carbonate show similar reactivity towards $\mathrm{OH}$ radicals. It is interesting to find the $\gamma^{\prime}\left(1^{\circ}\right)$ hydrogens having higher reactivity than $\alpha\left(1^{\circ}\right)$ and $\alpha^{\prime}\left(1^{\circ}\right)$ as the abstraction of $\mathrm{H}$ atom at the $\gamma^{\prime}\left(1^{\circ}\right)$ site occurs directly via a tight transition state requiring an energy barrier of about $12 \mathrm{~kJ} / \mathrm{mol}$, whereas the abstraction process occurring at the $\alpha\left(1^{\circ}\right)$ and $\alpha^{\prime}\left(1^{\circ}\right)$ sites involves addition-elimination mechanism (see reference ${ }^{39}$ ). For the latter process, transition states lie almost thermo-neutral relative to the un-complexed reactants (see Figs. 5 and 8 in reference $\left.{ }^{39}\right)$. Our findings for the $\gamma^{\prime}\left(1^{\circ}\right)$ hydrogens having higher reactivity than $\alpha\left(1^{\circ}\right)$ and $\alpha^{\prime}\left(1^{\circ}\right)$ are in line with the theoretical results of Mendes et al. ${ }^{39}$ as they concluded that the reactivity of ester hydrogens at the $\gamma$ positions is similar to that in alkanes and that the primary hydrogen in alkanes reacts faster than the $\alpha\left(1^{\circ}\right)$ and $\alpha^{\prime}\left(1^{\circ}\right)$ hydrogens in esters. The $\mathrm{H}$-atom abstraction at $\beta^{\prime}\left(1^{\circ}\right)$ site of esters also involves an addition-elimination process where the corresponding transition state lies higher than that of the $\alpha\left(1^{\circ}\right)$ abstraction. ${ }^{39}$ Therefore, the $\beta^{\prime}\left(1^{\circ}\right)$ hydrogens are found to have the least reactivity among all C-H sites for straight chain methyl esters over the temperature range of $800-1300 \mathrm{~K}$. The most labile hydrogen atom appears to be at $\alpha(0)$ position which reacts almost three times faster with $\mathrm{OH}$ radicals than that of $\alpha\left(1^{\circ}\right)$ or $\alpha^{\prime}\left(1^{\circ}\right)$ sites. This explains why methyl formate exhibits similar overall reactivity like dimethyl carbonate and methyl acetate (see Figure 3). The site-specific rates obtained here may be used to calculate overall rate coefficients for the reactions of larger chain methyl esters with $\mathrm{OH}$ radicals.

With the availability of the site-specific rates for the reaction of hydrogen abstraction from methyl esters by $\mathrm{OH}$ radicals, the branching ratios of various sites can be readily calculated. In Figure 9, branching ratios for the competing channels are plotted and compared with the results from 
Mendes et $a l .{ }^{39}$ and Westbrook et al. ${ }^{51}$ The branching ratios for straight chain methyl esters with $\mathrm{OH}$ radicals show interesting patterns.

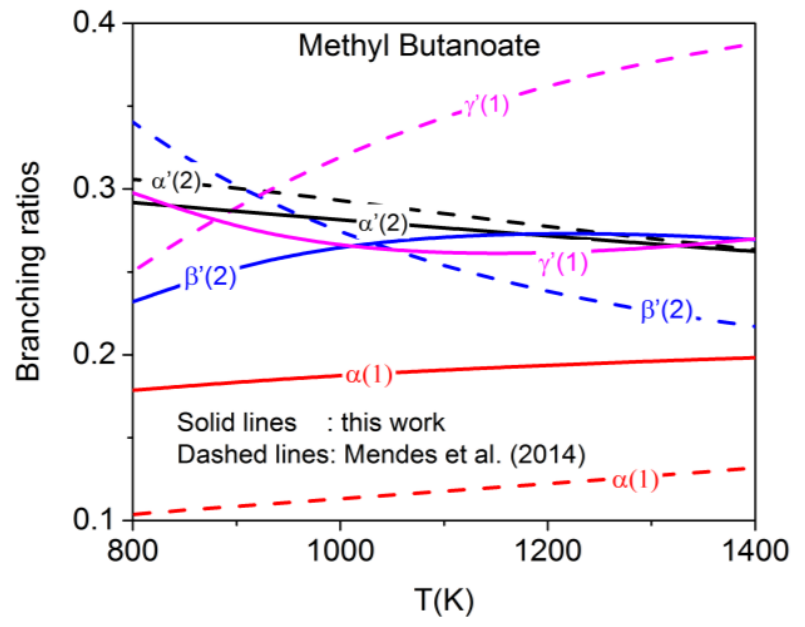

(a)

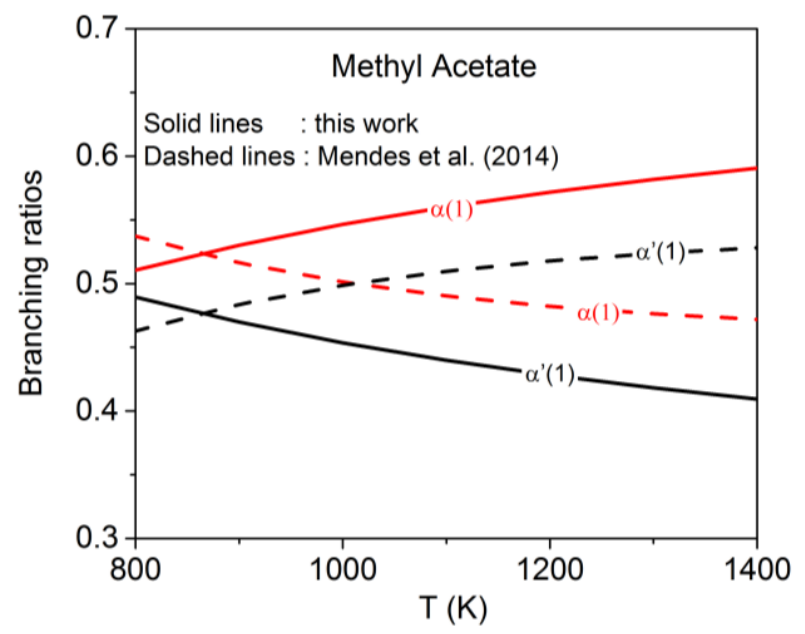

(c)

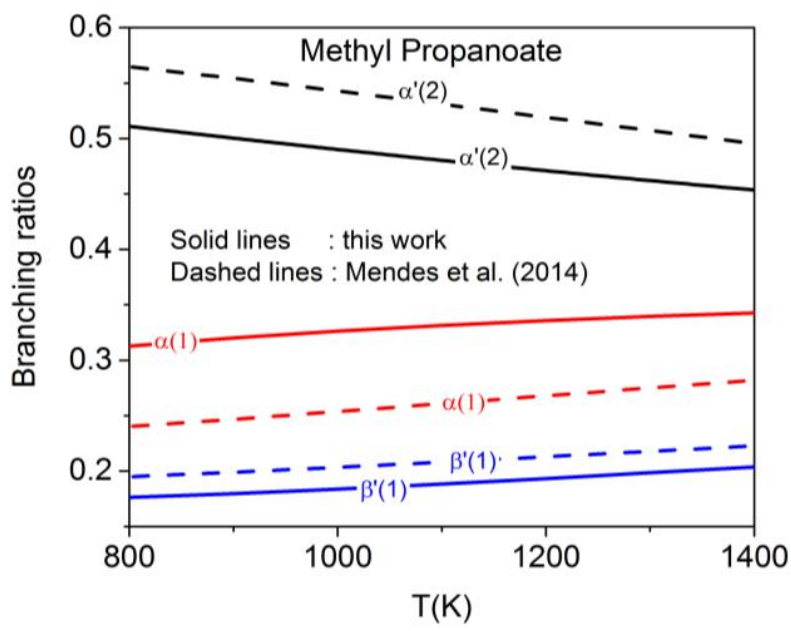

(b)

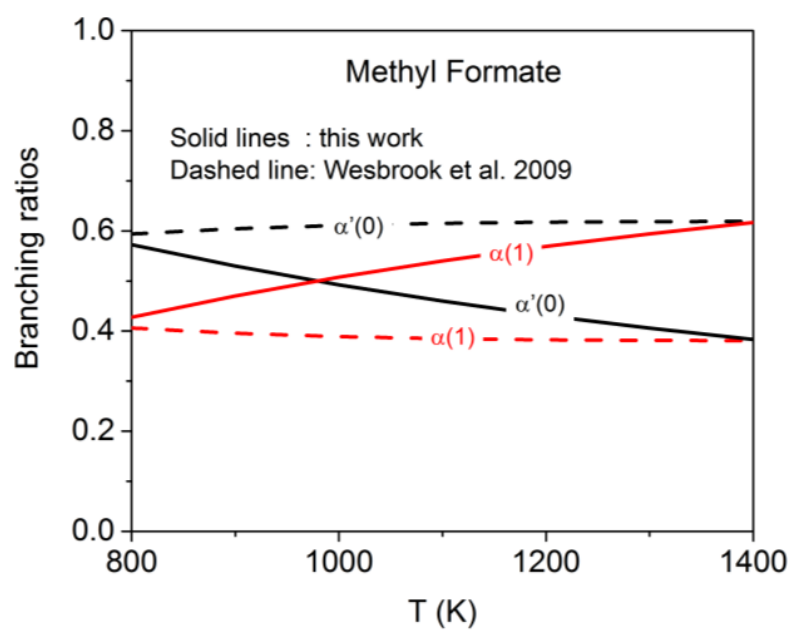

(d)

Figure 9: Branching ratios of the competing channels during $\mathrm{H}$-abstraction by $\mathrm{OH}$ from (a) methyl butanoate, (b) methyl propanoate, (c) methyl acetate and (d) methyl formate.

In general, our calculated values of the branching ratios for a given channel of methyl esters $+\mathrm{OH}$ reaction show reasonable agreement with literature values. In all cases, our values of the branching 
ratios of $\alpha\left(1^{\circ}\right) \mathrm{H}$-abstraction channel for methyl esters are underestimated by the theoretical prediction of Mendes et al. ${ }^{39}$ We note here that their theoretical values of the overall rate coefficients for the straight chain methyl esters and $\mathrm{OH}$ reactions are found to be consistently lower (at least 40\%) than the corresponding data for methyl esters $+\mathrm{OH}$ reactions measured experimentally by Lam et al. ${ }^{6}$

\section{Conclusions}

Rate coefficients for the hydrogen abstraction reaction of dimethyl carbonate (DMC) and $\mathrm{OH}$ radicals were measured experimentally using shock tube/laser absorption technique over the temperature range of $870-1300 \mathrm{~K}$. Theoretical rate coefficients were calculated by employing $a b$ initio and RRKM/master equation methodologies. Potential energy surface for the reaction of dimethyl carbonate and $\mathrm{OH}$ radicals was constructed using $\operatorname{CCSD}(\mathrm{T}) / \mathrm{cc}-\mathrm{pV} X \mathrm{Z}$ (where $X=\mathrm{D}$, T)//MP2/aug-cc-pVDZ level of theory. Among the conformers, cis-cis conformer of dimethyl carbonate, i.e., $c, c$-DMC, was found to be the most stable conformer. However, cis-trans $(c, t-$ DMC) was also found to be kinetically relevant at high temperatures. The $c, t$-DMC conformer lies about $13.1 \mathrm{~kJ} / \mathrm{mol}$ higher in energy than the $c, c$-DMC conformer which can be attained by overcoming an energy barrier of $40.1 \mathrm{~kJ} / \mathrm{mol}$. Analogous to other oxygenated organic compounds $+\mathrm{OH}$ reactions, the reaction of $\mathrm{DMC}$ and $\mathrm{OH}$ radicals proceeds via addition-elimination mechanism. We systematically searched for all possible complexes and found complexes in both the entrance and exit channels. For both conformers, the reaction which occurs via the formation of hydrogen bond between $\mathrm{H}$ atom of $\mathrm{OH}$ radical and $\mathrm{O}$ atom of the carbonyl group of DMC was found to be kinetically the most favorable channel. Our calculated values of rate coefficients are found to be in excellent agreement with our experimentally measured data. 
Furthermore, the results obtained for $\mathrm{DMC}+\mathrm{OH}$ reaction were combined with existing literature data for straight chain methyl esters and $\mathrm{OH}$ radical reactions to elucidate site-specific hydrogen abstraction rate coefficients. Our results show that the hydrogen atom at the $\alpha(0)$ site is the most reactive one followed by the secondary hydrogen atoms at the $\alpha^{\prime}$ and $\beta^{\prime}$ sites, whereas $\beta^{\prime}\left(1^{\circ}\right)$ hydrogens are found to have the least reactivity among all C-H sites for straight chain methyl esters over the temperature range of $800-1300 \mathrm{~K}$. The hydrogen atoms at the $\alpha\left(1^{\circ}\right)$ and $\alpha^{\prime}\left(1^{\circ}\right)$ positions are found to have similar reactivity and this results in both methyl acetate and dimethyl carbonate exhibiting very similar reactivity with $\mathrm{OH}$ radicals.

\section{Acknowledgements}

Research reported in this publication was supported by the King Abdullah University of Science and Technology (KAUST) under the Clean Combustion Research Center's CCF program on Future Fuels. Dr. Milán Szőri acknowledges Hungarian Academy of Sciences (BO/00113/15/7) for János Bolyai Research Scholarship and Magyary Zoltán Fellowship provided by the State of Hungary and the European Union within the framework of TÁMOP 4.2.4.A/2-11-1-2012-0001 "National Excellence Program" under the respective grant number of A2-MZPD-12-0139. The computations described in this work were performed on the research computing facilities at KAUST, the computing facility at the University of Szeged, Hungary, and the International University Laboratory for Computational Biochemistry, Institute for Computational Science and Technology at Ho Chi Minh City, Vietnam. The authors further thank László Müller and Máté Labádi of University of Szeged for administrating the computing systems.

\section{Supplementary Information}

Supplementary Material associated with this article can be found online. 


\section{References}

1. $\quad$ S. L. Peukert, R. Sivaramakrishnan and J. V. Michael, J. Phys. Chem. A, 2013, 117, 37293738 .

2. A. K. Agarwal, Prog. Energy Combust. Sci., 2007, 33, 233-271.

3. A. Farooq, D. F. Davidson, R. K. Hanson, L. K. Huynh and A. Violi, Proc. Combust. Inst., 2009, 32, 247-253.

4. S. L. Peukert, R. Sivaramakrishnan and J. V. Michael, J. Phys. Chem. A, 2013, 117, 37183728 .

5. P. A. Glaude, W. J. Pitz and M. J. Thomson, Proc. Combust. Inst., 2005, 30, 1111-1118.

6. K.-Y. Lam, D. F. Davidson and R. K. Hanson, J. Phys. Chem. A, 2012, 116, 12229-12241.

7. N. Cohen, Int. J. Chem. Kinet., 1991, 23, 397-417.

8. M. Szori, C. Fittschen, I. G. Csizmadia and B. Viskolcz, J. Chem. Theory Comput., 2006, $2,1575-1586$.

9. C. Bänsch, J. Kiecherer, M. Szöri and M. Olzmann, J. Phys. Chem. A, 2013, 117, 83438351.

10. C. Møller and M. S. Plesset, Phys. Rev., 1934, 46, 618-622.

11. K. B. Wiberg, In Ab Initio Molecular Orbital Theory, Wiley, New York, 1986.

12. T. H. Dunning, J. Chem. Phys., 1989, 90, 1007.

13. R. A. Kendall, T. H. Dunning and R. J. Harrison, J. Chem. Phys., 1992, 96, 6796.

14. J. P. Merrick, D. Moran and L. Radom, J. Phys. Chem. A, 2007, 111, 11683-11700.

15. C. Gonzalez and H. B. Schlegel, J. Phys. Chem., 1990, 94, 5523-5527.

16. C. Gonzalez and H. B. Schlegel, J. Chem. Phys., 1989, 90, 2154-2161.

17. G. D. Purvis and R. J. Bartlett, J. Chem. Phys., 1982, 76, 1910-1918.

18. G. E. Scuseria, C. L. Janssen and H. F. Schaefer, J. Chem. Phys., 1988, 89, 7382.

19. G. E. Scuseria and H. F. Schaefer, J. Chem. Phys., 1989, 90, 3700. 
20. L. Masgrau, A. n. González-Lafont and J. M. Lluch, J. Chem. Phys, 2001, 115, 4515.

21. D. G. Truhlar, Chem. Phys. Lett., 1998, 294, 45-48.

22. T. J. Lee and P. R. Taylor, Int. J. Quantum Chem., 1989, 199-207.

23. J. A. Montgomery, M. J. Frisch, J. W. Ochterski and G. A. Petersson, J. Chem. Phys., 2000, 112,6532 .

24. J. W. Ochterski, G. A. Petersson and J. A. Montgomery, J. Chem. Phys., 1996, 104, 2598.

25. L. A. Curtiss, K. Raghavachari, P. C. Redfern, V. Rassolov and J. A. Pople, J. Chem. Phys, 1998, 109, 7764.

26. L. A. Curtiss, P. C. Redfern and K. Raghavachari, J. Chem. Phys., 2007, 126, 084108.

27. M. J. Frisch, G. W. Trucks, H. B. Schlegel, G. E. Scuseria, M. A. Robb, J. R. Cheeseman, G. Scalmani, V. Barone, B. Mennucci, G. A. Petersson, H. Nakatsuji, M. Caricato, X. Li, H. P. Hratchian, A. F. Izmaylov, J. Bloino, G. Zheng, J. L. Sonnenberg, M. Hada, M. Ehara, K. Toyota, R. Fukuda, J. Hasegawa, M. Ishida, T. Nakajima, Y. Honda, O. Kitao, H. Nakai, T. Vreven, J. J. A. Montgomery, J. E. Peralta, F. Ogliaro, M. Bearpark, J. J. Heyd, E. Brothers, K. N. Kudin, V. N. Staroverov, R. Kobayashi, J. Normand, K. Raghavachari, A. Rendell, J. C. Burant, S. S. Iyengar, J. Tomasi, M. Cossi, N. Rega, J. M. Millam, M. Klene, J. E. Knox, J. B. Cross, V. Bakken, C. Adamo, J. Jaramillo, R. Gomperts, R. E. Stratmann, O. Yazyev, A. J. Austin, R. Cammi, C. Pomelli, J. W. Ochterski, R. L. Martin, K. Morokuma, V. G. Zakrzewski, G. A. Voth, P. Salvador, J. J. Dannenberg, S. Dapprich, A. D. Daniels, Ö. Farkas, J. B. Foresman, J. V. Ortiz, J. Cioslowski and D. J. Fox, Gaussian, Inc., Wallingford CT, 2009.

28. M. V. Duong, H. T. Nguyen, N. Truong, T. N. M. Le and L. K. Huynh, Int. J. Chem. Kinet., $2015,47,564-575$.

29. T. V. T. Mai, M. v. Duong, X. T. Le, L. K. Huynh and A. Ratkiewicz, Struct. Chem., 2014, $25,1495-1503$.

30. J. Badra, A. E. Elwardany, F. Khaled, S. S. Vasu and A. Farooq, Combust. Flame, 2014, $161,725-734$.

31. J. N. Bradley, Shock Waves in Chemistry and Physics, Methuen, 1962.

32. A. Lifshitz, Shock Waves in Chemistry, Taylor \& Francis, 1981.

33. V. Vasudevan, D. F. Davidson and R. K. Hanson, J. Phys. Chem. A, 2005, 109, 3352-3359.

34. J. Badra, F. Khaled, B. R. Giri and A. Farooq, Phys. Chem. Chem. Phys., 2015, 17, 24212431.

35. D. F. Davidson, M. Roehrig, E. L. Petersen, M. D. Di Rosa and R. K. Hanson, J. Quant. Spectrosc. Radiat. Transfer, 1996, 55, 755-762. 
36. E. C. Rea, A. Y. Chang and R. K. Hanson, J. Quant. Spectrosc. Radiat. Transfer, 1987, 37, 117-127.

37. G. A. Pang, R. K. Hanson, D. M. Golden and C. T. Bowman, Z. Phys. Chem., 2011, 225, 1157-1178.

38. I. Reaction Design, San Diego, CA, CHEMKIN PRO Release 15101 edn., 2010.

39. J. Mendes, C.-W. Zhou and H. J. Curran, J. Phys. Chem. A, 2014, 118, 4889-4899.

40. S. K. Reddy and S. Balasubramanian, J. Phys. Chem. B, 2012, 116, 14892-14902.

41. C. Bansch, J. Kiecherer, M. Szori and M. Olzmann, J. Phys. Chem. A, 2013, 117, 83438351.

42. A. Galano and J. Raúl Alvarez-Idaboy, in Adv. Quantum Chem., eds. E. G. Michael and S. J. Matthew, Academic Press, 2008, vol. Volume 55, pp. 245-274.

43. C.-W. Zhou, J. M. Simmie and H. J. Curran, Phys. Chem. Chem. Phys., 2010, 12, 72217233.

44. C.-W. Zhou, J. M. Simmie and H. J. Curran, Phys. Chem. Chem. Phys., 2011, 13, 1117511192.

45. C.-W. Zhou, J. M. Simmie and H. J. Curran, Combust. Flame, 2011, 158, 726-731.

46. T. Tan, X. Yang, C. M. Krauter, Y. Ju and E. A. Carter, J. Phys. Chem. A, 2015, 119, 63776390.

47. B. R. Giri, F. Khaled, M. Szőri, B. Viskolcz and A. Farooq, Proc. Combust. Inst., DOI: http://dx.doi.org/10.1016/j.proci.2016.06.016.

48. B. E. Poling, J. M. Prausnitz and J. P. O'Connel, The Properties of Gases and Liquids, 5th ed., McGraw-Hill Education, New York, Chicago, San Francisco, Athens, London, Madrid, Mexico City, Milan, New Delhi, Singapore, Sydney, Toronto, 2004.

49. T. V. T. Mai, X. T. Le and L. K. Huynh, Struct. Chem., 2014, 26, 431-444.

50. R. Sivaramakrishnan and J. V. Michael, J. Phys. Chem. A, 2009, 113, 5047-5060.

51. C. K. Westbrook, W. J. Pitz, P. R. Westmoreland, F. L. Dryer, M. Chaos, P. Osswald, K. Kohse-Höinghaus, T. A. Cool, J. Wang, B. Yang, N. Hansen and T. Kasper, Proc. Combust. Inst., 2009, 32, 221-228. 